\title{
ŚRODKOWOEUROPEJSKIE SPOŁECZNOŚCI OSAD OBRONNYCH W 1. POL. II TYSIĄCLECIA BC. STUDIUM PORÓWNAWCZE OBSZARÓW PRÓBNYCH
}

\author{
CENTRAL EUROPEAN SOCIETIES OF FORTIFIED SETTLEMENTS \\ IN THE FIRST HALF OF THE $2^{\text {ND }}$ MILLENNIUM BC. \\ A COMPARATIVE STUDY OF TRIAL AREAS
}

\author{
(autoreferat wygłoszony w trakcie obrony pracy doktorskiej \\ w dniu 24 czerwca 2011 r.)
}

\begin{abstract}
Przedkładana dysertacja dotyczy problematyki środkowoeuropejskich społeczności osad obronnych $\mathrm{w}$ okresie 1 . poł. II tysiąclecia p.n.e. Praca przygotowana została w języku angielskim. Tworzy ją 7 rozdziałów poprzedzonych wstępem. Pracę zamykają ujęte w osobną wypowiedź wnioski. Tekst liczy 179 stron i zilustrowany został 59 rycinami, z 8 mapami włącznie. Wykorzystana $\mathrm{w}$ trakcie realizacji pracy literatura przedstawiona została w liczącej 43 strony bibliografii.

W sposób zasadniczy prezentowaną rozprawę podzielić można na trzy części: wprowadzającą, źródłoznawczą oraz podsumowującą. Pierwsza z nich zawiera wstęp oraz rozdziały 1 i 2 poświęcone odpowiednio historii badań nad osadnictwem obronnym oraz krytyce dostępnych, wykorzystanych źródeł. We wstępie zarysowane zostały podstawowe cele badawcze pracy. Scharakteryzowano ponadto panujące w obecnej dyskusji nad zagadnieniem poglądy postrzegające, w wyniku powierzchownego i wybiórczego traktowania źródeł archeologicznych, zjawisko powstawania osad obronnych na rozległym obszarze Europy Środkowej jako fenomenu homogenicznego, często genetycznie wiązanego z wpływem cywilizacyjnym strefy egejsko-anatolijskiej. Zarysowano przyjętą formułę postępowania badawczego bazującą na aspektowej analizie osadnictwa obronnego w wybranych obszarach próbnych. Dobór badanych zmiennych jest konsekwencją przyjętego założenia, w myśl którego osady obronne ogniskują w sobie najistotniejsze cechy epoki, takie jak: intensyfikacja dalekosiężnych powiązań, wewnątrzregionalnej wymiany, stratyfikacji społecznej, rozwoju gospodarki i rzemiosła $\mathrm{z}$ metalurgią brązu na czele. Wymienione cechy tradycyjnie przypisuje się analizowanym społecznościom, stąd decyzja o poddaniu krytyce źródeł, które powinny stanowić ich materialną manifestację. Zgodnie $\mathrm{z}$ tym kolejnymi analizowanymi aspektami są:
\end{abstract}


gospodarka i środowisko naturalne, zabudowa wewnętrzna, umocnienia oraz metalurgia. Źródła z nimi związane powinny odzwierciedlać poziom rozwoju badanych społeczności. Niezależnie od przywołanego założenia omówiono także kwestie chronologiczne. Rozdziały poświęcone poszczególnym obszarom próbnym każdorazowo zamyka dyskusja nad określonymi propozycjami interpretacyjnymi dotyczącymi roli i funkcji osad obronnych.

Dobór obszarów próbnych podyktowany był przede wszystkim obecnym stanem wiedzy na temat osadnictwa obronnego $\mathrm{w}$ ich obrębie. Wyselekcjonowano obszary o długiej tradycji badawczej. Jedynie tak uzasadniony wybór gwarantował realizację zamierzonych celów. Analizie zdecydowano się poddać cztery obszary próbne: strefę alpejską i związane z nią tzw. ugrupowania wewnątrzalpejskiej epoki brązu, południowo-zachodnią Wielkopolskę, Bruszczewo z grupą kościańską kultury unietyckiej, strefę środkowego Dunaju z kulturą Vatya oraz obszar górnej Cisy leżący we wschodniej części Słowacji, z kulturą Otomani-Füzesabony.

Rozdział 1 poświęcony jest historii badań nad interesującum mnie zagadnieniem. Została ona opisana osobno w odniesieniu do poszczególnych obszarów próbnych. Ponadto przywołano najistotniejsze opracowania pokonferencyjne, stanowiące do tej pory najpełniejsze zbiory informacji dotyczących osadnictwa obronnego epoki brązu.

Istotnym elementem wstępnej części prezentowanej dysertacji jest rozdział 2. W jego ramach scharakteryzowano źródła, z jakich korzystano w trakcie realizacji pracy. Literatura przedmiotu $\mathrm{w}$ omawianym przypadku to bardzo rozległy i rozproszony zbiór tekstów (praktycznie całkowicie pozbawiony monografii poszczególnych stanowisk), często jedynie o charakterze przyczynkarskim. W znacznej części stanowią je artykuły zawarte w lokalnych periodykach. Koniecznością była praca $\mathrm{z}$ tekstami tworzonymi w odmiennych tradycjach badawczych, odzwierciedlonych chociażby w dużej ilości lokalnych schematów chronologii względnej oraz określonych strategiach prowadzenia badań wykopaliskowych. Ostatnie z wymienionych wymagały szczegółowego scharakteryzowania.

We wschodniej części Słowacji, objętej osadnictwem kultury Otomani-Füzesabony, badania od blisko 70 lat koncentrowały się praktycznie wyłącznie na osadach obronnych. Mimo to rozpoznano wykopaliskowo zaledwie kilka z nich. Do najistotniejszych, analizowanych w pracy, należą: Košice-Barca, Nižná Myšl'a, Spišský Štvrtok oraz Rozhanovce. Badania wymienionych stanowisk, choć prowadzone przez wiele sezonów (w przypadku Nižnej Myšl'i już ok. 40 lat) nie zaowocowały jak dotąd monograficznymi opracowaniami. Osady te znane są przede wszystkim z przyczynkarskich publikacji skupiających się w głównej mierze na spektakularnych znaleziskach. W efekcie osady obronne kultury Otomani-Füzesabony ze wschodniej Słowacji dyskutuje się od lat w europejskiej prahistoriografii praktycznie wyłącznie przez pryzmat efektownych zabytków z brązu, złota i bursztynu, pozostawiając całkowicie na marginesie dalece bardziej istotne kwestie, jak np. relacja do środowiska naturalnego, gospodarka czy chronologia absolutna. W tym kontekście omówiono charakter prowadzonych dotychczas 
badań wykopaliskowych - praktycznie pozbawiony elementów współpracy ze specjalistami z zakresu nauk przyrodniczych oraz technik pozyskiwania części źródeł faunistycznych i botanicznych (m.in. brak przemywania, przesiewania obiektów archeologicznych).

Szereg informacji prezentowanych przez archeologów z byłej Czechosłowacji doprowadził do rozwinięcia intensywnej dyskusji o potencjalnych związkach (również o charakterze genetycznym) osadnictwa obronnego kultury Otomani-Füzesabony ze strefą egejsko-anatolijską, a zwłaszcza z kulturą mykeńską. Przez dziesięciolecia w dyskusji tej za podstawowy argument mający potwierdzać wspomniane dalekosiężne relacje służyły kamienne fortyfikacje osady Spišský Štvrtok. W omawianym rozdziale wyraźnie zaznaczono nikły stan wiedzy o stanowisku. Za szczególnie istotny problem uznano fakt, iż podstawową publikacją wykorzystywaną bezkrytycznie przez archeologię europejską od blisko półwiecza jest kilkunastostronicowy tekst autorstwa J. Vladára (1975), zamieszczony w przewodniku wycieczki dla uczestników sympozjum archeologicznego w Bratysławie.

W odniesieniu do osadnictwa obronnego z dorzecza środkowego Dunaju za najistotniejszy problem uznać należy, podobnie jak w przypadku wschodniej Słowacji, stan i sposób publikacji wyników badań wykopaliskowych oraz stosowaną w ich trakcie metodykę. Podstawowe kontrowersje wiążą się z wiarygodnym ustaleniem liczby osad obronnych na omawianym obszarze. Przyjęta w prezentowanej pracy liczba 32 najczęściej pojawia się w literaturze przedmiotu. Większość osad rozpoznana została jedynie w wyniku badań powierzchniowych i pomiarów wysokościowych. Wykopaliskowo zbadano zaledwie $14 \mathrm{z}$ nich. W większości przypadków były to badania prowadzone na niewielką skalę, a ich wyniki nie stały się przedmiotem publikacji. Dysponujemy zaledwie dwoma opracowaniami monograficznymi i jednym szerszym raportem $\mathrm{w}$ formie artykułu. Dodatkową komplikację stanowi stosowana w trakcie badań na osadach technika wykopaliskowa zwana Spatenstichtechnik. Terminem tym określa się kopanie na głębokość łopaty. Ze względu na tellowy charakter większości stanowisk obronnych kultury Vatya taki sposób prowadzenia badań wykopaliskowych uniemożliwiał rzetelną obserwację i dokumentowanie sytuacji stratygraficznej oraz porządkowanie źródeł, chociażby zgodnie z przebiegiem warstw naturalnych. Ponadto w trakcie większości badań nie gromadzono pełnego zbioru materiałów faunistycznych, skupiając się przede wszystkim na formach narzędziowych oraz dobrze zachowanych, dużych fragmentach kości. Podobnie negatywny wpływ technik wykopaliskowych na jakość pozyskiwanych źródeł obserwować można w przypadku makroszczątków roślinnych. Zaledwie jedno stanowisko (Százhalombatta) badane jest interdyscyplinarnie. W ramach tego projektu z otoczenia osady pozyskano profile palinologiczne oraz poddano analizie źródła faunistyczne.

Należy ponadto podkreślić, iż tematyka ogólnie pojętej kultury Vatya, w tym zagadnienia poświęcone osadnictwu obronnemu, od dziesięcioleci były ignorowane przez archeologię europejską. Problem ten podejmowany był praktycznie wyłącznie przez badaczy węgierskich. 
W strefie alpejskiej, podobnie jak w omówionych powyżej przypadkach, badania koncentrują się na osadach obronnych. Szczególnie szeroko dyskutuje się ich potencjalny związek z eksploatacją lokalnych złóż miedzi. Relatywnie niewielka ilość osad obronnych nie stanowi zbioru dobrze rozpoznanego i prezentowanego w literaturze przedmiotu. Dysponujemy zaledwie jedną monografią stanowiska St. Veit Klinglberg, które jednak ze względu na stan zachowania nie dostarczyło szeregu istotnych informacji. Z kolei efekty prac interdyscyplinarnego projektu badań archeologicznych osady Bartholomäberg (Friaga Wald) prezentowane są praktycznie w niezmiennej formie w szeregu krótkich opracowań autorstwa R. Krause. Zaznaczyć jednak należy, iż dostarczyły one profili palinologicznych, co dało pewien wgląd w tematykę relacji człowiek środowisko.

Relatywnie dobrze na tle pozostałych obszarów próbnych prezentuje się osada w Bruszczewie (Wielkopolska). Badana w ramach długoletniego, interdyscyplinarnego projektu dostarczyła szeregu istotnych informacji. Waga pozyskanych danych wiąże się zarówno z unikatowym stanem zachowania źródeł w strefie torfowej, jak i wyjątkową skalą zastosowania procedur badawczych łączących możliwości analityczne archeologii oraz nauk przyrodniczych. Obszar próbny południowo-zachodniej Wielkopolski jest w kontekście prezentowanej pracy wyjątkowy. Zawiera się w nim zaledwie jedna osad obronna.

Reasumując, należy wskazać, iż w większości wybranych obszarów próbnych istnieją znaczące braki w stanie wiedzy i publikacji wyników badań wykopaliskowych. Ostatnie z wymienionych często nie były prowadzone w sposób gwarantujący pozyskiwanie wiarygodnych zbiorów źródeł. Ponadto $\mathrm{w}$ żadnym $\mathrm{z}$ analizowanych przypadków nie dysponujemy odpowiednią wiedzą o innych niż obronne formach osadniczych. Ograniczało to w sposób znaczący możliwości analityczne autora.

Druga część pracy zawiera analizę poszczególnych obszarów próbnych. Kolejno w rozdziałach 3, 4, 5 i 6 omawiane są określone powyżej aspekty funkcjonowania społeczności osad obronnych (odpowiednio są to rozdziały 3.1-3.6, 4.1-4.6, 5.1-5.6 i 6.16.6). Ta część pracy stanowi jej rdzeń. W świetle dotychczasowych badań nad zagadnieniem zawarte w niej informacje są pierwszą próbą krytycznej analizy materiałów archeologicznych pochodzących z osad obronnych, dokonaną na podstawie właściwych tekstów źródłowych. Pod pojęciem tych ostatnich rozumie się faktyczne wyjściowe raporty z badań wykopaliskowych. Dotychczasowa praktyka archeologii europejskiej polegała na bezkrytycznym korzystaniu z określonego, relatywnie krótkiego, kanonu tekstów, często zawierających jedynie interpretację pierwotnych informacji. W omawianych rozdziałach zawarta została szczegółowa analiza źródeł pochodzących bezpośrednio z osad obronnych. Rygorystyczny pod tym względem sposób selekcji materiałów archeologicznych stanowi wyraźną alternatywę dla popularnego podejścia interkontekstualnego, promowanego m. in. przez K. Kristiansena i T. B. Larssona (2005), T. Earle'a (2010) oraz C. Uhnéra (2010). Pozwala ono na sięganie po źródła z osad o różnej atrybucji kulturowej, z różnych obszarów Europy Środkowej (z różnych kontekstów) w celu zbu- 
dowania syntetycznego ujęcia badanego zjawiska. W rozdziałach poświęconych analizie aspektowej obszarów próbnych przedstawiono liczne cechy społeczności osad obronnych, które tłumaczyć należy silną tradycją lokalną. Widoczna jest ona w wielu analizowanych elementach. Wymienić należy przede wszystkim tellowy charakter i wewnętrzny podział charakteryzujący osady obszaru środkowego Dunaju, wznoszenie wyłącznie kamiennych fortyfikacji w strefie alpejskiej i drewniano-ziemnych umocnień wokół osad kultury Otomani-Füzesabony. W kontekście ostatniej z wymienionych należy podkreślić, iż właśnie krytyczna analiza zebranych informacji dotyczących „otomańskiego” budownictwa obronnego pozwoliła na reinterpretację zakorzenionego w archeologii europejskiej poglądu o brązowej metryce kamiennych umocnień osady Spišský Štvrtok. Tym samym, w kontekście cech architektury obronnej w Kotlinie Karpackiej, zakwestionowana została opinia o intensywnych kontaktach lokalnych społeczności z kulturą mykeńską.

Dalszymi istotnymi elementami omawianej części pracy są rozdziały poświęcone chronologii. Zaprezentowane zostały zestawienia dostępnych datowań radiowęglowych. Poddano je krytycznej analizie pod kątem jakości prób, sposobu publikacji i ogólnej wiarygodności dla rozważań chronologii absolutnej osadnictwa obronnego w poszczególnych obszarach próbnych. Dla stanowisk w Bruszczewie (kultura unietycka) oraz Kakucs-Balla-domb (dorzecze środkowego Dunaju, kultura Vatya) zaprezentowane zostały nowe datowania radiowęglowe. W tych przypadkach, gdzie było to możliwe, przytoczono ponadto informacje dotyczące chronologii względnej. Zaznaczyć jednak należy, iż z wyłączeniem Bruszczewa, w którego przypadku analiza materiału ceramicznego stała się obiektem osobnego opracowania, oraz osady w Százhalombatta, nie dysponujemy schematami typochronologicznymi, którym towarzyszyłaby publikacja stosownych materiałów archeologicznych.

Zebrane w toku aspektowej analizy informacje pozwoliły na przeprowadzenie porównania poszczególnych obszarów próbnych (rozdział 7) oraz na wskazanie licznych białych plam i zmitologizowanych poglądów istniejących w aktualnej wiedzy. Problemy, jakie ujawniono w scharakteryzowanej części pracy, mają różną naturę. Często są to kwestie prozaiczne, które jednak niosą za sobą poważne konsekwencje. W tym kontekście należy przede wszystkim wskazać na brak publikacji planów osad z precyzyjną informacją o ich zawartości archeologicznej i skali badań wykopaliskowych. W wielu przypadkach dysponujemy jedynie wycinkami planów płaskich prezentującymi fragmenty chat oraz innych obiektów. To właśnie na ich podstawie budowane są nawet najbardziej śmiałe tezy o potencjale demograficznym, sposobie organizacji przestrzeni, ale również o głębszych zjawiskach natury społecznej. Istotnym problemem jest również bardzo skromna ilość datowań radiowęglowych. Szczególnie znaczące jest to w odniesieniu do obszarów próbnych z Kotliny Karpackiej. Zlokalizowane tam stanowiska cechują się największą komplikacją, często mają charakter tellowy. Pochodzące z nich pojedyncze daty radiowęglowe nie pozwalają na analizę wielu istotnych zjawisk związanych z potencjalną dynamiką procesu osadniczego. W tym kontekście znaczący jest również nikły stan rozpoznania złożonej stratygrafii stanowisk. Właściwie w żadnym 
z analizowanych przykładów nie zbadano i nie zadokumentowano pełnej sekwencji stratygraficznej. Ponadto mimo że w przypadku większości stanowisk mówić możemy zapewne o długotrwałym osadnictwie, nie dysponujemy źródłami przyrodniczymi, które pozwoliłyby określić charakter relacji „,złowiek - środowisko” oraz skalę antropopresji. Jak istotne są to kwestie ukazuje przykład Bruszczewa, który przyniósł dowody znaczącej degradacji środowiska naturalnego w toku osadnictwa wczesnej epoki brązu.

Trzecią, podsumowującą, część prezentowanej pracy stanowi analiza porównawcza zawarta w rozdziale 7 oraz przedstawione osobno konkluzje.

W ramach analizy porównawczej wskazano zarówno podobieństwa, jak i różnice dzielące analizowane obszary próbne. Pierwszy wskazany poziom odmienności odnosi się do podziału w makroskali na obszary położone na północ (południowo-zachodnia Wielkopolska i strefa alpejska) oraz południe (dorzecze środkowego Dunaju i górnej Cisy) od łuku Karpat. Charakteryzują się one przede wszystkim odmienną tradycją budownictwa obronnego. W przypadku Kotliny Karpackiej, do pewnego stopnia, mówić można o odtwarzaniu wzorców osadniczych obecnych na tym obszarze już w neolicie (szczególnie w odniesieniu do dzisiejszych Węgier). Ponadto w obu strefach odmiennie rozwijała się metalurgia brązu. W tym kontekście różnice odnoszą się zarówno do stylistyki, zwyczajów związanych z deponowaniem przedmiotów brązowych, jak i odmiennych strategii przyjmowania oraz wykorzystywania innowacji metalurgii.

Drugi poziom zróżnicowania analizowanych obszarów odnosi się do cech dzielących zarówno poszczególne regiony, jak i określone osady w ich obrębie. W tym wypadku analizę wszystkich opisanych aspektów omawianych społeczności utrudniał różny stopień ich rozpoznania archeologicznego. W omawianym rozdziale podkreślono trwałość neolitycznej tradycji kulturowej widocznej w podziale Kotliny Karpackiej na obszary, których osią odpowiednio były Dunaj (kultura Vatya) i Cisa (kultura Otomani-Füzesabony). Mimo widocznych dzielących je różnic scharakteryzowane zostały źródła wskazujące na istnienie procesu intensyfikacji kontaktów wewnątrzkarpackich na przełomie środkowej i późnej epoki brązu (w terminologii węgierskiej). Ponadto podkreślono rolę dwóch najistotniejszych generatorów wymiany epoki - bursztynu i brązu - w formowaniu się relacji łączących strefę północnych obszarów próbnych z południowymi.

Różnice zadokumentowane w sposobach wznoszenia fortyfikacji oraz szacowanych wielkości populacji poszczególnych osad posłużyły za podstawę rozważań nad militarną funkcjonalnością osad obronnych. Zasadniczo dla omawianego odcinka epoki brązu odrzucono możliwość istnienia bezpośredniego związku pomiędzy powstawaniem osad obronnych a występowaniem realnego i stałego zagrożenia. Zwłaszcza najbardziej masywne umocnienia uznane zostały przede wszystkim za swoistą formę manifestacji siły i możliwości organizacyjnych określonych społeczności.

Pracę zamykają ujęte $\mathrm{w}$ osobną wypowiedź konkluzje. Zawierają one przede wszystkim postulat konieczności zmiany strategii badań nad osadnictwem obronnym. Ustalenia dokonane $\mathrm{w}$ prezentowanej pracy oraz krytyka zabranych źródeł stanowić 
powinny punkt wyjścia do dalszych studiów nad problematyką społeczności osad obronnych epoki brązu. Dopiero na kolejnym etapie możliwe będzie zastosowanie złożonych modeli teoretycznych. Należy podkreślić, iż tworzenie nowego obrazu społeczności epoki brązu musi zostać oparte na interdyscyplinarnie rozpoznanych stanowiskach. W konfrontacji z obiektami cechującymi się tak wysoce skomplikowaną strukturą oraz bogactwem źródeł jak osady obronne (zwłaszcza osady tellowe), archeologia bez odwołania się do doświadczeń nauk przyrodniczych nie dysponuje wystarczającymi możliwościami analitycznymi.

\section{CENTRAL EUROPEAN SOCIETIES OF FORTIFIED SETTLEMENTS IN THE FIRST HALF OF THE $2^{\text {ND }}$ MILLENIUM BC. COMPARATIVE STUDY OF TRIAL AREAS}

\section{S u m m a ry}

The dissertation is aimed at a description and characterization of the central European societies of fortified settlements in the first half of the 2nd millenium BC. Because of the high number of such sites and different stage of research in particular regions, it was necessary to select the sources. Four trial areas were chosen: Alpine area, south-western Wielkopolska, middle Danube basin and upper Tisa basin. All of them were related to different cultural units: inner-Alpine Bronze Age groups, Unetice culture, Vatya culture and Otomani-Füzesabony culture. The crucial criteria for selecting trial areas was long research tradition and store of knowledge about fortified settlements characterizing them. In order to show regional variability of the fortified settlements there were described their different aspects. Particular chapters contain information about: economy and natural environment, inner layout, fortifications, metallurgy and chronology. Moreover there was discussed the role and function of the defensive structures in particular regions. In the final chapter the author summarizes the results of his comparative analyses.

Mateusz Jaeger

Instytut Kultury Europejskiej, Uniwersytet im. Adama Mickiewicza w Poznaniu

ul. J. Kostrzewskiego 5-7, 62-200 Gniezno, Poland 